\title{
Infecção do trato urinário em gestantes: uma revisão integrativa
}

\author{
Urinary tract infection in pregnant women: an integrative review \\ Infección del tracto urinario en mujeres embarazadas: una revisión integradora
}

Recebido: 22/10/2021 | Revisado: 29/10/2021 | Aceito: 04/11/2021 | Publicado: 09/11/2021

\author{
Larissa Botelho da Silva \\ https://orcid.org/0000-0002-4400-6565 \\ Centro Universitário do Vale do Ipojuca/Wyden, Brasil \\ E-mail: larissabotelho488@gmail.com \\ Pâmella Grasielle Vital Dias de Souza \\ https://orcid.org/0000-0001-9884-9544 \\ Centro Universitário do Vale do Ipojuca/Wyden, Brasil \\ E-mail: pamellagvds@gmail.com
}

\begin{abstract}
Resumo
As infecções do trato urinário (ITU), são consideradas a complicação clínica mais frequente na gestação, ela surge devido uma falha no sistema de defesa contra os agentes instalados que podem provocar lesões de graus diversificados tanto para mãe quanto para o feto. O presente estudo aponta os principais agentes microbiológicos, as classificações clínicas, complicações advindas e condutas terapêuticas. Foi realizada uma revisão de literatura integrativa, utilizando artigos publicados entre os anos de 2016 e 2021, nas línguas portuguesa, inglesa e espanhola que foram publicados de forma íntegra nos bancos de dados PubMed, SciELO, LILACS e DeCS. As ITUs na gestação são causadas por fatores hormonais, anatômicos e fisiológicos, essas condições promovem o crescimento bacteriano. Essas infecções são normalmente ocasionadas por bactérias da microbiota intestinal que contaminam o trato urinário, destacando-se com maior predominância a Escherichia coli com $80 \%$ dos casos. Para um tratamento eficaz é preciso identificar a bactéria causadora da infecção, para selecionar o antibiótico adequado. Portanto, para a redução e controle dos casos de infecções do trato urinário, devem ser realizadas consultas de pré-natal e exames precoces para diagnosticar a infecção a fim de precaver possíveis complicações perinatais e maternas.
\end{abstract}

Palavras-chave: Infecção do trato urinário; Gravidez; Bactéria.

\begin{abstract}
Urinary tract infections (UTI) are considered the most frequent clinical complication in pregnancy, it arises due to a failure in the defense system against installed agents that can cause injuries of varying degrees for both the mother and the fetus. The present study points out the main microbiological agents, clinical classifications, complications arising and therapeutic approaches. An integrative literature review was carried out, using articles published between 2016 and 2021, in Portuguese, English and Spanish, which were published in full in the PubMed, SciELO and LILACS databases. UTIs in pregnancy are caused by hormonal, anatomical and physiological factors, these conditions promote the bacterial growth of this pathology. These infections are usually caused by bacteria from the intestinal microbiota that contaminate the urinary tract, with Escherichia coli standing out most predominantly in $80 \%$ of cases. For an effective treatment it is necessary to determine the bacteria causing the infection, to select the appropriate antibiotic. Therefore, to reduce and control cases of tract infections, prenatal consultations and early examinations to diagnose the infection should be carried out in order to prevent possible perinatal and maternal complications.
\end{abstract}

Keywords: Urinary tract infection; Pregnancy; Bacterium.

\section{Resumen}

Las infecciones del tracto urinario (ITU) se consideran la complicación clínica más frecuente durante el embarazo; se producen por un fallo en el sistema de defensa contra los agentes instalados, que pueden causar lesiones de diverso grado tanto para la madre como para el feto. Este estudio señala los principales agentes microbiológicos, las clasificaciones clínicas, las complicaciones y los enfoques terapéuticos. Se realizó una revisión de literatura integradora, utilizando artículos publicados entre los años 2016 y 2021, en las lenguas portuguesa, inglesa y española que fueron publicados de forma íntegra en los bancos de datos PubMed, SciELO y LILACS. Las ITU durante el embarazo están causadas por factores hormonales, anatómicos y fisiológicos; estas condiciones favorecen el crecimiento bacteriano en esta patología. Estas infecciones suelen estar causadas por bacterias de la microbiota intestinal que contaminan el tracto urinario, siendo Escherichia coli la más frecuente, con un $80 \%$ de los casos. Para un tratamiento eficaz es necesario determinar la bacteria que causa la infección para seleccionar el antibiótico adecuado. Por lo tanto, para reducir y controlar los casos de infecciones del tracto, se deben realizar consultas 
prenatales y exámenes tempranos para diagnosticar la infección con el fin de prevenir posibles complicaciones perinatales y maternas.

Palabras clave: Infección del tracto urinario; Embarazo; Bacterias.

\section{Introdução}

A infecção do trato urinário (ITU) está entre as infecções bacterianas mais comuns nas mulheres, principalmente quando gestantes. Essa patologia surge após uma falha no sistema de defesa ligado à virulência da bactéria e à suscetibilidade do hospedeiro contra os agentes instalados, substituindo a microbiota feminina por bactérias uropatogênicas que ascendem pelo trato urinário e coloniza-se na vagina e na uretra distal, ocasionando processos patológicos (Haddad \& Fernandes, 2018).

A ITU pode ser classificada como complicada e não complicada. São complicadas quando acomete o sistema urinário realizando modificações funcionais e não complicadas quando agravam o sistema urinário normal. A caracterização também se faz segundo a localização anatômica, em alta ou baixa. As infecções baixas são infecções que afetam a uretra e a bexiga, são designadas de bacteriúria assintomática, uretrite e cistite. As altas podem afetar os rins ou as cavidades pielocaliciais, indicativo de pielonefrite aguda (Abreu Silva et al., 2019).

A Escherichia coli é o tipo de patógeno mais presente, encontrado em maior proporção em gestantes com infecções não complicadas. Em outros casos é possível encontrar as espécies: Enterococcus; Klebsiella; Pseudomonas; Enterococcus ou Staphylococcus. A contaminação do trato urogenital também se faz através de fungos da cavidade vaginal, como é o caso das infecções provocadas pelo fungo Candida ssp (Lee et al., 2018; Sabih \& Leslie, 2021).

A presença de bactérias no trato urinário, provocam diferentes desfechos negativos no quadro da gestante. As complicações maternas e perinatais possuem maior ocorrência nos quadros de pielonefrite. Destacam-se com maior prevalência o parto pré-termo, recém nascido com retardo mental e baixo peso, disúria, polaciúria ou em casos mais graves o óbito neonatal (Veiga et al., 2017).

O estudo deste tema é de grande relevância considerando a elevada incidência de infecções urinárias no período gestacional e dos agravos na saúde da mulher e do feto. É de suma importância a conscientização quanto a atenção das consultas e exames periódicos bem como o pré-natal para o diagnóstico e tratamento precoce, pois quanto mais tardia a sua descoberta, maiores serão os riscos. Essa revisão tem como objetivo apontar os principais agentes etiológicos relacionados a infecção, apresentar as diferentes classificações, identificar as complicações advindas e expor condutas terapêuticas.

\section{Metodologia}

A revisão de literatura integrativa trata-se de um estudo de cunho qualitativo e caráter descritivo e exploratório baseados nos métodos descritos por Pereira et al., (2018), onde relata que a pesquisa é feita através de materiais e trabalhos já realizados, tendo como objetivo analisar artigos e pesquisas relacionadas com o tema: infecção do trato urinário em gestantes, classificações, complicações, etiologia e tratamento. Com intuito de adquirir dados a cerca do assunto, colaborando com a população e estudos científicos.

Para realização desse estudo, foram aplicados como critérios de inclusão a seleção de artigos e revistas que abordassem assuntos relacionados ao tema em questão, publicados entre os anos de 2016 e 2021, em idiomas da língua portuguesa, inglesa ou espanhola que estejam disponíveis em forma íntegra. Foram selecionados os artigos acadêmicos e revistas disponibilizados nas plataformas cientificas e banco de dados como: Scientific Eletronic Library Online (SciELO), Literatura Latino-Americana e do Caribe em Ciências da Saúde (LILACS), National Library of Medicine (PubMed) e Descritores em Ciências da Saúde (DeCS), utilizando os descritores: infecção do trato urinário (ITU); gravidez; bactéria. Combinados entre se com operadores 
booleanos AND ou OR. Após a análise de dados e leitura de títulos e resumos foram pré-selecionados 20 artigos para formação e construção do material. O esquema utilizado para a escolha dos artigos está representado na Figura 1.

Figura 1: Esquema para seleção de artigos.

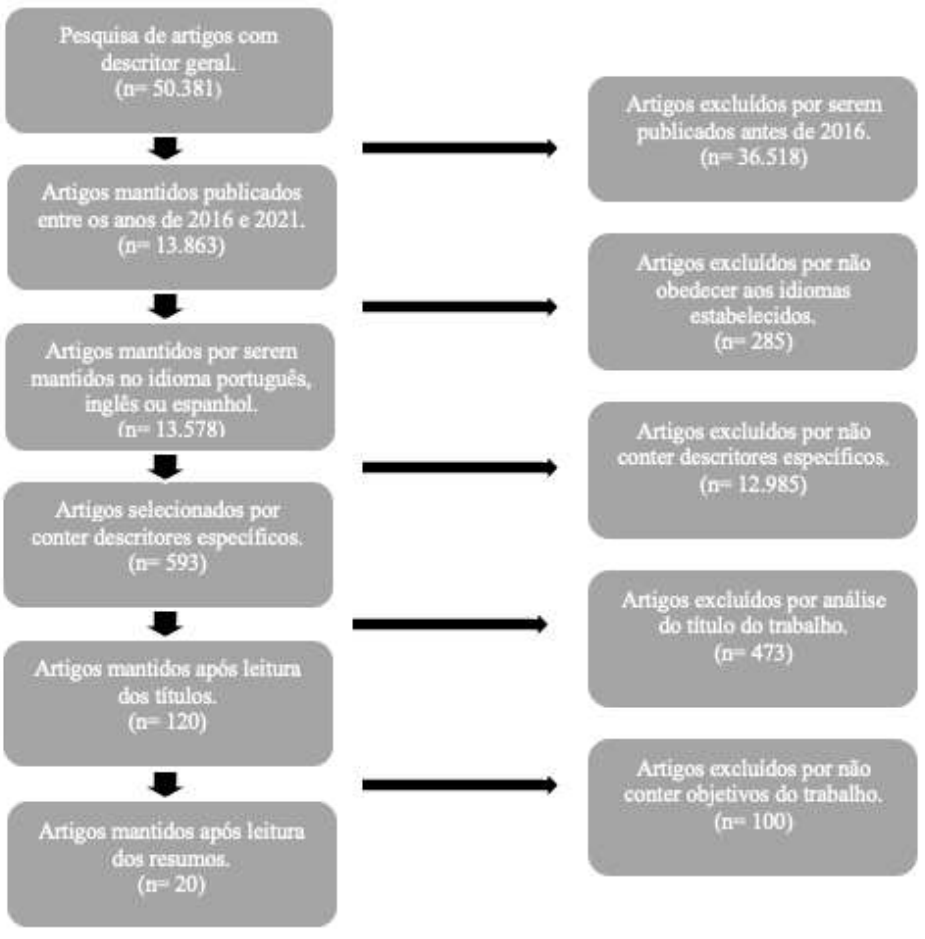

Fonte: Autores.

Para análise e síntese deste estudo, foram usados quadros sinópticos de fluxograma para seleção de artigos que atendessem aos critérios de inclusão do trabalho, para isso, são considerados alguns aspectos pertinentes como: título da pesquisa; autores; ano de publicação; intervenção estudada; recomendação e conclusão. Foram descartados todos os materiais que não atenderam aos critérios de inclusão, como: artigos publicados em anos anteriores a 2016; trabalhos incompletos e que não seguiam o objetivo do trabalho e artigos que não atendiam aos idiomas estabelecidos. A apresentação dos resultados e discussão dos dados obtidos foi realizada de forma descritiva por meio de uma revisão integrativa, de forma a atingir o objetivo desse método e da pesquisa.

\section{Resultados e Discussão}

No decorrer da pesquisa, foram encontrados cerca de 18.299 artigos com o descritor infecção urinária, posteriormente foi feito uma nova consulta com outros descritores e filtros indicados anteriormente na metodologia, a fim de afunilar a pesquisa e encontrar os materiais de maior relevância para compor este estudo, buscando explorar a bibliografia mais atual possível. No final da busca, foram selecionados 20 artigos para leitura e criação do artigo.

Após a análise das literaturas selecionadas, foi possível verificar que as ITUs acometem toda a população em geral, desde crianças até adultos de ambos os sexos. Segundo Santos et al., (2019) e Geerlings, (2016), 40\% das infecções urinárias provocadas por bactérias acometem o sexo feminino, sendo $17 \%$ a $20 \%$ dessas mulheres durante o período gestacional, atingem também mulheres na pré-menopausa (1,9\%), mulheres diagnosticadas com diabetes (12\% à $14 \%)$ e sexo masculino (2,3\%), conforme descreve o Quadro 1. No entanto, as grávidas se destacam como o mais susceptível a desenvolver essa infecção, devido 
as diversas transformações anatômicas, fisiológicas e hormonais que surgem no decorrer da gestação e auxiliam na proliferação das bactérias e fungos (Gupta et al., 2017).

Quadro 1: Prevalência de ITU em populações selecionadas.

\begin{tabular}{cc} 
População & $\begin{array}{c}\text { Prevalência } \\
(\%)\end{array}$ \\
\hline Mulheres & $40 \%$
\end{tabular}

Mulheres gravidas

Pré-menopausa

Pacientes com diabetes

Sexo masculino
$17 \%$ a $20 \%$

$1,9 \%$

$12 \%$ a $14 \%$

$2,3 \%$

Fonte: Autores.

São vários os fatores que estão relacionados com a infecção do trato urinário, destacam-se como mais vistos nessas populações: as mudanças hormonais; uretra curta; dilatação dos ureteres; atividade sexual; pH da urina e aumento do volume da bexiga. Todas essas condições promovem a estase urinária, facilitando ainda mais o crescimento bacteriano dessa patologia (Kalinderi et al., 2018).

Para Santos et al., (2019), cerca de 40\% das mulheres terão algum episódio de infecção em um momento da sua vida, inclusive no período ciclo gravídico, sendo $20 \%$ delas eventos recorrentes. A ITU é considerada a infecção com maior índice de intercorrência nos atendimentos médicos, apresentando maior predominância em gestantes diagnosticadas com bacteriúria assintomática (BA), (10\% dos casos). A BA apesar de não apresentar manifestações clínicas, requer maior atenção dos profissionais de saúde, pois, se não tratada precocemente pode acarretar um grave quadro de pielonefrite.

Entre os agentes etiológicos que podem causar ITU na gestante, a Escherichia coli é o uropatógeno mais frequente, responsável por aproximadamente $80 \%$ dos casos seguido de outros microrganismos como as enterobactérias (Enterobacter, Klebsiela pneumoniae (6,7\%), Proteus mirabilis (3,5\%), Staphylococcus saprophyticus (10\%), Streptococcus do grupo B., Staphylococcus Epidermidise, Enterococcus faecalis (4\%). Alguns fungos ou leveduras também podem estar envolvidos, como por exemplo a Candida e Chlamydia trachomatis (3,4\%). Esses microrganismos podem acarretar serias lesões de graus diversificados tanto para a mãe quanto para o feto, de acordo com sua localização anatômica e nível de infecção (Coria et al., 2018; Santos Filho \& Telini, 2018).

Vários métodos são usados para triagem e diagnóstico de uma ITU, inicia-se com uma análise primária observando os sintomas apresentado pela paciente, em seguida o exame de fita da urina, outro método é o teste de urocultura considerado o exame padrão-ouro, tem como valor de referência $\geq 10.000$ ufc / $\mathrm{mL}$ (unidades formadoras de colônias), A microscopia da urina também pode ser útil na detecção de bactérias. Por fim, teste de sensibilidade antimicrobiano como complementação para melhor confirmação do resultado clínico (Geerlings, 2016; Kalinderi et al., 2018). 


\section{Formas clínicas da infecção do trato urinário}

Mulheres grávidas com infecção do trato urinário podem apresentar sintomas ou permanecerem assintomáticos. Sendo assintomáticas de 10 a 20 vezes a mais que a sintomática. Quando se trata das classificações clínicas, diversos sintomas e aspectos são avaliados no aparecimento dessas bactérias. As entidades clínicas abrangidas pelo termo "ITU" incluem bacteriúria assintomática (BA), uretrite, cistite e pielonefrite (Gupta et al., 2017).

A bacteriúria assintomática (BA) na gravidez é definida através da proliferação de bactérias na urina sem a presença de sintomas clínicos, como a própria nomenclatura indica. Globalmente, a prevalência da BA é estimada em 2-11\% das gestantes. A pesquisa de bacteriúria assintomática em mulheres grávidas é recomendada entre a $12^{\mathrm{a}}$ e $16^{\mathrm{a}}$ semanas de gestação. Pelo menos uma cultura de urina é necessária no fim do primeiro trimestre e no segundo ou início do terceiro. A bacteriúria pode ser confirmada por cultura de urina, na qual as bactérias da amostra são analisadas para identificar o número e a espécie de bactéria. Sua ocorrência apresenta ligação direta com a pielonefrite (Nteziyaremye et al., 2020).

A uretrite é um acometimento uretral, conhecido clinicamente como desconforto ao urinar (disúria) e aumento da frequência urinário, porém com menor volume urinário (polaciúria). Em grande parte dos casos, as mulheres não apresentam quadros de bacteriúria significativa. Os principais agentes envolvidos na formação da uretrite são as bactérias e fungos frequentemente encontrados na cavidade vaginal, como: Chlamydia trachomatis, Staphylococcus sp e Candida albicans (Young et al., 2021).

A infecção do trato urinário baixo ou cistite, é uma enfermidade sintomática que acomete a bexiga urinária. De acordo com, Li \& Leslie, (2021), a cistite pode ser categorizada como simples ou complicada. A cistite simples, refere-se a infeções em mulheres não-grávidas que são saudáveis. A cistite complicada, por outro lado, está associada a fatores de riscos e mulheresgrávidas. A ascensão de bactérias da bexiga pode levar à infecção renal (pielonefrite). Habitualmente, as gestantes diagnosticadas com cistite, apresentam indícios de sintomas como: disúria com ou sem aumento de frequência, urgência miccional, hematúria e dor suprabúbica. A cistite pode ser diferenciada da pielonefrite pela ausência de achados sistêmicos, como febre, calafrios ou sepse (Flores-Mireles et al., 2019; Geerlings, 2016).

Conceitualmente, a pielonefrite é a infecção bacteriana mais invasiva e preocupante, considerada a forma mais crítica dessa patologia. Ela causa inflamação dos rins e de suas estruturas adjacentes. A pielonefrite surge como uma complicação da infecção não tratada precocemente (bacteriúria assintomática), permitindo que ocorra a proliferação das bactérias na bexiga de forma ascendente em direção para os rins e sistemas coletores. Os sintomas mais comuns são: febre, dor lombar, náuseas e vômitos. Em geral, cerca de $20 \%$ a 30\% das gestantes desenvolverão pielonefrite aguda, isso acontece na maioria das vezes durante o segundo e o terceiro trimestre (Belyayeva \& Jeong, 2021; Habak \& Griggs, Jr, 2021).

As infecções do trato urinário é uma das complicações infecciosas mais frequentes durante a gravidez, com incidência de $8 \%$ e maior risco entre as semanas 22 e 24 . Segundo estudos realizados, esse agravo acomete aproximadamente 150 milhões de pessoas por ano, em todo o mundo, representando um fardo significativo para o sistema de saúde (Coria et al., 2018; Marcon et al., 2017).

\section{Complicações advindas da infecção}

As complicações provenientes da infecção do trato urinário exercem um impacto significativo em mulheres em todo o mundo. Essa infecção, apresenta-se clinicamente com uma variedade de sinais e sintomas que podem ser causadas por diferentes organismos a depender do tipo adquirido, agravando tanto o prognóstico materno quanto o perinatal (McLellan \& Hunstad, 2016). 
Os agravos maternos são decorrentes do dano tecidual ocasionado pelo aparecimento de bactérias no trato que predispõe o surgimento de bacteriúria assintomática ou sintomática. Algumas dessas complicações estão associadas a imunomodulação (controle das reações imunológicas de um organismo por um agente) do período gestacional. Estudos prospectivos demonstram complicações frequentes como: náuseas; vômitos; febre; calafrios; dor intensa; dor supra púbica; choque séptico; bacteremia; obstrução renal; abcesso renal ou perineal e insuficiência renal (Santos Filho \& Telini, 2018).

Dentre as complicações perinatais advindas da infecção do trato, destacam-se o trabalho de parto pré-termo; recémnascidos de baixo peso; paralisia cerebral; ruptura prematura da membrana amniótica; deficiência intelectual e óbito perinatal. As principais causas da elevada mortalidade perinatal concentram-se na prematuridade, no baixo peso ao nascer e nas infecções neonatais. Os sintomas clínicos podem variar em cada indivíduo, segundo a virulência do microrganismo (Santos Filho \& Telini, 2018).

A ITU é a causa de fundamentais complicações na gravidez. Diversas dessas complicações podem ser prevenidas com acompanhamento pré-natal e tratamento executado adequadamente. A infecção urinária é uma preocupação significativa que merece atenção dos profissionais de saúde, uma vez que a incidência dessa doença está cada dia maior (McLellan \& Hunstad, 2016).

\section{Conduta terapêutica de tratamento para itu}

A escolha do tratamento em gestante depende de alguns fatores, são eles: manifestações clínicas, sintomas apresentados pela paciente e de um adequado diagnóstico. Uma vez que a bacteriúria é diagnosticada na gravidez, mesmo que assintomática, a conduta terapêutica com antibióticos pode ser iniciada. Algumas ITUs são simples, e por isso podem ser tratadas com antibióticos ambulatoriais. Por outro lado, as infecções complicadas apresentam maior falha de tratamento e maior risco a saúde, normalmente requerem a utilização de medicamentos com uso mais prolongados e de alguns exames complementares (Sabih \& Leslie, 2021).

A BA e cistite aguda são tratadas com terapia antibiótica. Em mulheres com sintomas de cistite sem febre ou sinais de infecção sistêmica, é recomendada antibioticoterapia oral ambulatorial. A escolha do antibiótico pode ser ajustada com base na sensibilidade do organismo, quando disponível a partir dos resultados da cultura de urina associado ao resultado do antibiograma, que deve ser solicitado pelo médico. Os cursos de antibióticos de um dia não são recomendados na gravidez, embora os cursos de 3 dias sejam eficazes. Os antibióticos comumente usados incluem amoxicilina, ampicilina, cefalosporinas, nitrofurantoína (cura clínica de 79\% a 92\%). Aproximadamente 12,8\% das pacientes apresentam infecção recorrente, nesses casos recomenda-se profilaxia contínua geralmente por um tempo de 3 a 6 meses. Assim como o plano terapêutico, algumas medidas preventivas também podem ser adotadas como: hidratação adequada, micções frequentes, evitar constipação, micção após o ato sexual e higiene anal no sentido anteroposterior (Wingert et al., 2019).

A pielonefrite na gravidez é uma infecção perigosa e grave que geralmente requer hospitalização. Assim que o diagnóstico é concluído, o tratamento é iniciado. A febre deve ser tratada com uma manta de resfriamento e antibióticos se necessário. Comumente, as cefalosporinas de segunda ou terceira geração são utilizadas para o tratamento inicial. Ampicilina ou outros antibióticos são de uso alternativos, pois os mesmos estão relacionados a alergia e reações anafiláticas. Os pacientes devem ser monitorados de perto para o desenvolvimento de agravamento da sepse (Habak \& Griggs, Jr, 2021).

A posologia recomendada no tratamento da infecção em gestantes para cada fármaco é: cefalosporina (um comprimido de 500mg em intervalos de 6 horas), nitrofurantoína (um comprimido de 100mg em intervalos de 6 horas), ampicilina (um comprimido de 500mg em intervalos de 6 horas), amoxicilina (um comprimido de 500mg em intervalos de 6 horas). Conforme está descrito no Quadro 2. Na maioria dos casos, a resposta ao tratamento deve ser evidente em 24 a 48 horas. Caso não 
evidenciado, aconselha-se a repetição do exame antibiograma para entender o perfil de sensibilidade e resistência do microrganismo identificado. Esses fármacos empregados no tratamento das ITUs são, na maioria das vezes eficazes, pois são excretados pelo rim, sem metabolização prévia significativa (Habak \& Griggs, Jr, 2021).

Quadro 2: Antibióticos orais para ITU e suas posologias.

\begin{tabular}{cc}
\hline Antibióticos & \multicolumn{1}{c}{ Posologias } \\
\hline Cefalosporina & $500 \mathrm{mg}$ a cada 6 horas \\
Nitrofuratoína & $100 \mathrm{mg}$ a cada 6 horas \\
Ampicilina & $500 \mathrm{mg}$ a cada 6 horas \\
& $500 \mathrm{mg}$ a cada 6 horas \\
\hline
\end{tabular}

Fonte: Autores.

A conduta terapêutica para bacteriúria se subdivide em quatro padrões de respostas quando exposto ao antibiótico: cura, persistência bacteriológica, recaída e reinfecção. A persistência bacteriológica é a insistência da bacteriúria com o mesmo microrganismo após 48 horas de tratamento, pode estar relacionada a terapia inadequada. Recaída é uma infecção com o mesmo microrganismo que causou a infecção inicial do tratamento. Uma recaída indica que o organismo infectante persistiu no trato urinário. A reinfecção é uma infecção após a esterilização da urina. Na maioria das vezes, há uma mudança nas espécies bacterianas. É muito importante determinar em qual tipo de padrão a gestante se enquadra para que a escolha do medicamento seja adequada (Geerlings, 2016).

Para a diminuição e controle de casos de ITU, cabe a toda equipe de saúde envolvida, realizar a educação da paciente quanto o assunto e sua gravidade, orienta-la quanto a coleta de urina, solicitar exames precocemente no pré-natal para diagnosticar e tratar os casos de ITU, e instituindo tratamento antimicrobiano mais adequado e eficaz, quanto mais cedo a ITU for gerenciada, melhores serão os resultados (De Abreu Silva et al., 2019).

\section{Considerações Finais}

A ITU é um evento frequente durante a gravidez, por causa das modificações anatômicas e fisiológicas no corpo da mulher e as alterações funcionais que as tornam suscetível ao uropatógeno com maior facilidade. Sabendo do risco aumentado para o desenvolvimento dessa patologia na gestação, da possibilidade de ocorrência de bacteriúria assintomática e das complicações maternas e perinatais é imprescindível a realização de uroculturas e exames de urina nas gestantes, sendo recomendados a cada trimestre da gestação.

Resultados de estudos demonstram que devem ser realizadas medidas preventivas no processo das consultas periódicas (pré-natal), com objetivo de precaver possíveis complicações clínicas para a mãe e o bebê. Ressalta também a importância da detecção precoce, a fim de que exista a devida orientação terapêutica para uma atenção eficaz, principalmente no que diz respeito a gravidez.

As terapias de tratamento disponíveis atualmente, não evoluíram significativamente nos últimos anos. Sabe-se que elas não previnem as infecções recorrentes nas gestantes e são frequentemente desafiadas pelo aumento da resistência aos 
antibióticos. Por isso, vê-se necessário novos estudos a cerca de uma compreensão completa a respeito de novas condutas terapêuticas para serem administradas em mulheres grávidas. Visto que uma das maiores dificuldades, encontra-se mediante o estado gravídico e sua restrição medicamentosa.

\section{Referências}

Belyayeva, M., \& Jeong, J. M. (2021). Acute Pyelonephritis. In StatPearls. http://www.ncbi.nlm.nih.gov/pubmed/30137822

Coria, M. del P., Guzzetti, P., Suárez, M., Vigliarolo, L., Viegas Caetano, J. A., \& Lopardo, H. (2018). Infecciones urinarias por Streptococcus agalactiae y Staphylococcus saprophyticus y embarazo. Acta Bioquím. Clín. Latinoam, 52(4), 423-428.

De Abreu Silva, R., Araújo de Sousa, T., \& De Assis Vitorino, K. (2019). Infecção Do Trato Urinário Na Gestação: Diagnóstico E Tratamento. Revista Científica FAEMA, 10(1), 71-80. https://doi.org/10.31072/rcf.v10iedesp.765

Flores-Mireles, A., Hreha, T. N., \& Hunstad, D. A. (2019). Pathophysiology, treatment, and prevention of catheter-associated urinary tract infection. Topics in Spinal Cord Injury Rehabilitation, 25(3), 228-240. https://doi.org/10.1310/sci2503-228

Geerlings, S. E. (2016). Clinical presentations and epidemiology of urinary tract infections. Urinary Tract Infections: Molecular Pathogenesis and Clinical Management, 27-40. https://doi.org/10.1128/9781555817404.ch2

Gupta, K., Grigoryan, L., \& Trautner, B. (2017). In the clinic ${ }^{\circledR}$ urinary tract infection. Annals of Internal Medicine, 167(7), ITC49-ITC64. https://doi.org/10.7326/AITC201710030

Habak, P. J., \& Griggs, Jr, R. P. (2021). Urinary Tract Infection In Pregnancy. In StatPearls. http://www.ncbi.nlm.nih.gov/pubmed/30725732

Haddad, J. M., \& Fernandes, D. A. O. (2018). Infecção Do Trato. Femina, 47(4), 241-244. https://www.febrasgo.

Kalinderi, K., Delkos, D., Kalinderis, M., Athanasiadis, A., \& Kalogiannidis, I. (2018). Urinary tract infection during pregnancy: current concepts on a common multifaceted problem. Journal of Obstetrics and Gynaecology, 38(4), 448-453. https://doi.org/10.1080/01443615.2017.1370579

Lee, D. S., Lee, S. J., Choe, H. S., \& Giacobbe, D. R. (2018). Community-Acquired Urinary Tract Infection by Escherichia coli in the Era of Antibiotic Resistance. BioMed Research International, 2018. https://doi.org/10.1155/2018/7656752

Li, R., \& Leslie, S. W. (2021). Cystitis. In StatPearls. http://www.ncbi.nlm.nih.gov/pubmed/29494042

Marcon, J., Stief, C. G., \& Magistro, G. (2017). Harnwegsinfektionen. Der Internist, 58(12), 1242-1249. https://doi.org/10.1007/s00108-017-0340-y

McLellan, L. K., \& Hunstad, D. A. (2016). Urinary Tract Infection: Pathogenesis and Outlook. Trends in Molecular Medicine, $22(11)$, 946-957. https://doi.org/10.1016/j.molmed.2016.09.003

Nteziyaremye, J., Iramiot, S. J., Nekaka, R., Musaba, M. W., Wandabwa, J., Kisegerwa, E., \& Kiondo, P. (2020). Asymptomatic bacteriuria among pregnant women attending antenatal care at Mbale Hospital, Eastern Uganda. PLoS ONE, 15(3), 1-12. https://doi.org/10.1371/journal.pone.0230523

Pereira, A., Shitsuka, D., Parreira, F., \& Shitsuka, R. (2018). Método Qualitativo, Quantitativo ou Quali-Quanti. In Metodologia da Pesquisa Científica. https://repositorio.ufsm.br/bitstream/handle/1/15824/Lic_Computacao_Metodologia-Pesquisa-Cientifica.pdf?sequence=1. Acesso em: 28 março 2020.

Sabih, A., \& Leslie, S. W. (2021). Complicated Urinary Tract Infections. In StatPearls. http://www.ncbi.nlm.nih.gov/pubmed/28613784

Santos, C. C., Madeira, H. S., Silva, C. M. da, Teixeira, J. J. V., \& Peder, L. D. de. (2019). Prevalência de infecções urinárias e do trato genital em gestantes atendidas em Unidades Básicas de Saúde. Revista de Ciências Médicas, 27(3), 101. https://doi.org/10.24220/2318-0897v27n3a4115

Santos Filho, O. O., \& Telini, A. H. S. (2018). Infecções do trato urinário durante a gravidez. Federação Brasileira Das Associações de Ginecologia e Obstetrícia (FEBRASGO), 87, 24.

Veiga, S. P. da, BOEIRA, V. L., SILVA, C. M. da, \& PEDER, L. D. de. (2017). Incidência De Infecções Do Trato Urinário Em Gestantes E Correlação Com O Tempo De Duração Da Gestação. Acta Biomédica Brasiliensia, 8(1), 95. https://doi.org/10.18571/acbm.125

Wingert, A., Pillay, J., Sebastianski, M., Gates, M., Featherstone, R., Shave, K., Vandermeer, B., \& Hartling, L. (2019). Asymptomatic bacteriuria in pregnancy: systematic reviews of screening and treatment effectiveness and patient preferences. BMJ Open, 9(3), e021347. https://doi.org/10.1136/bmjopen-2017-021347

Young, A., Toncar, A., \& Wray, A. A. (2021). Urethritis. In StatPearls. https://pubmed.ncbi.nlm.nih.gov/30725967/ 